Int. J. Electrochem. Sci., 13 (2018) 4841 - 4854

\title{
In Vitro Characterization of Electrodeposited Hydroxyapatite Coatings on Titanium (Ti6AL4V) and Magnesium (AZ31) Alloys for Biomedical Application
}

\author{
R.B. Durairaj ${ }^{1}$, S. Ramachandran ${ }^{2, *}$ \\ ${ }^{1}$ Research Scholar, School of Mechanical Sciences, Sathyabama Institute of Science and Technology, \\ Chennai, India. \\ ${ }^{2}$ Research Professor, School of Mechanical Sciences, Sathyabama Institute of Science and \\ Technology, Chennai, India. \\ *E-mail: aishram2006@gmail.com
}

doi: $10.20964 / 2018.05 .85$

Received: 23 January 2018 / Accepted: 16 March 2018 / Published: 10 April 2018

\begin{abstract}
Metallic implant, which is widely used in orthopedic and dental applications, should be removed once the healing process is completed. Removal of implants requires another surgery with psychological stress and economic burden. Biodegradable metallic implants have attracted researcher's attention as these implants are degraded and absorbed in the human body after the healing process is done. Among the various degradable metals, magnesium and its alloys are found to have similar physiochemical characteristics to that of natural bone. However, fast degradation and high corrosion rates limit its efficient use as implants. Coating over magnesium alloys can limit the degradation and corrosion rates so as to make implants of tailor-made performance. In this paper, chemically synthesized hydroxyapatite (HA) is coated over titanium (Ti6AL4V) and magnesium alloy (AZ31) substrates by electrodeposition technique. The coated and uncoated samples are subjected to electrochemical corrosion to examine the corrosive behavior of the coatings. The in vitro examination is undergone in simulated body fluid solution to identify the formation of bio growth of the HA coated Magnesium and Titanium alloy samples. SEM, EDS, FTIR analyses are used for characterization of the coatings. The results are obtained and discussed. The results show that the degradation and corrosion rates of HA coated Ti6AL4V and AZ31are lower than that of uncoated samples. However, HA coated AZ31 seems to be a promising candidate for degradable implant applications as it supports bio-growth, while there is no significant bio-growth is observed in HA coated Ti6AL4V alloy.
\end{abstract}

Keywords: biomedical, hydroxyapatite, electro-deposition, magnesium, titanium, degradable implants, corrosion.

\section{FULL TEXT}


(C) 2018 The Authors. Published by ESG (www.electrochemsci.org). This article is an open access article distributed under the terms and conditions of the Creative Commons Attribution license (http://creativecommons.org/licenses/by/4.0/). 